\title{
AVALIAÇÃO DA FORÇA DE GEL DE SURIMI DE RESíDUOS DE PESCADA-FOGUETE (Macrodon ancylodon) ENRIQUECIDO COM ADITIVOS PROTÉICOS
}

\author{
CLÁUDIO RAFAEL KUHN * \\ GERMANO JORGE DORNELES SOARES ** \\ CARLOS PRENTICE-HERNÁNDEZ *** \\ JOÃO LUÍS DA SILVA VENDRUSCOLO****
}

\begin{abstract}
Aditivos protéicos (albumina de soro bovino e clara de ovo) foram adicionados ao surimi de resíduos do processamento de pescada-foguete (Macrodon ancylodon) para proteger a rede protéica miofibrilar e aumentar a força do gel kamaboko, formado durante o processamento térmico do surimi. Também adicionouse cloreto de amônio $\left(\mathrm{NH}_{4} \mathrm{Cl}\right)$ para inibir a transglutaminase, enzima cuja presença aumenta a textura devido melhor conformação das proteínas no pré-aquecimento. A análise instrumental em testes de compressão revelou que o surimi contendo aditivos alcançou maior força de gel em relação ao controle, sendo a albumina do soro bovino melhor do que a clara de ovo $(P<0,05)$. A utilização do $\mathrm{NH}_{4} \mathrm{Cl}$ não demonstrou interferência da transglutaminase nos géis, indicando ausência da enzima na espécie estudada. Nas condições empregadas não foi caracterizada proteólise capaz de desestruturar o gel.
\end{abstract}

PALAVRAS-CHAVE: SURIMI; ADITIVOS PROTÉICOS; FORÇA DE GEL; TRANSGLUTAMINASE.

* Mestre em Ciências, Doutorando, Departamento de Ciência e Tecnologia Agroindustrial (DCTA), Faculdade de Agronomia Eliseu Maciel (FAEM), Universidade Federal de Pelotas (UFPel), Campus Universitário, Pelotas, RS (e-mail: crkuhn@ig.com.br).

** Orientador, PhD. em Ciência e Tecnologia de Alimentos, Prof. Titular, DCTAFAEM-UFPel

*** Co-orientador, Doutor em Engenharia de Alimentos, Prof. Adjunto, DQMFURG, Rio Grande, RS.

**** Colaborador, Doutor em Ciência dos Alimentos, Pesquisador EMBRAPA CPACT - Pelotas, RS. 


\section{INTRODUÇÃO}

O gel protéico termoestável (kamaboko) em produtos à base de surimi pode ser comprometido pela ação de proteases não-removidas totalmente durante o processamento. Essas enzimas, principalmente as catepsinas e as peptidases alcalinas (estáveis ao calor são ativadas no tratamento térmico), degradam as miofibrilas (modori) com perdas na textura que é o principal indicador de qualidade desses produtos (AN et al., 1996; GARCÍA-CARREÑO, 1996).

Para a proteção da estrutura protéica miofibrilar são utilizados aditivos protéicos. Esses melhoram as propriedades físicas do gel e controlam a atividade das proteases (ótimo de atividade entre 55 e $65^{\circ} \mathrm{C}$ ), evitando a clivagem das proteínas do músculo (MORRISSEY et al., 1993). As proteínas do plasma bovino (PPB) destacam-se como as de melhor desempenho em relação a outros inibidores, como a clara de ovo e extrato de batata. No Brasil, ainda não há estudos direcionados para o melhor desenvolvimento de surimie produtos derivados, constituindo campo aberto à investigação científica em espécies nativas, tanto marinhas como de água doce (KUHN e SOARES, 2002).

Pretendeu-se no presente trabalho avaliar, por análise instrumental em testes de compressão, a força de gel do surimi de resíduos da pescada-foguete (Macrodon ancylodon), utilizando os aditivos protéicos albumina do soro bovino e clara de ovo. Também foi empregado o cloreto de amônio como inibidor da transglutaminase (enzima que contribui para maior estabilidade do gel), que pode estar naturalmente presente no músculo, favorecendo as ligações cruzadas entre as moléculas de proteína, principalmente, em etapas como préaquecimento (fenômeno denominado suwari).

\section{MATERIAL E MÉTODOS}

\subsection{PROCESSAMENTO DE SURIMI}

Carcaças inteiras de pescada-foguete (Macrodon ancylodon) foram coletadas na indústria e após a retirada da cabeça, vísceras e cauda, lavadas em água clorada (5 ppm). O espinhaço obtido foi conduzido para o processo de separação mecânica em despolpadeira (Baader, 
mod. 694, cilindro com perfurações de $5 \mathrm{~mm}$ de diâmetro) para obtenção da polpa. Essa foi lavada duas vezes em tanques de polietileno, utilizando-se água fria $\left(\mathrm{t}<10^{\circ} \mathrm{C}\right)$ na proporção $3: 1$ (água/ polpa, p/p), com concentração salina de 1\%, sob leve agitação durante 5 min e drenagem entre as lavagens. Após a segunda lavagem foi realizado o refino da polpa, por compressão, mediante malha de aço inox com 2 mm de diâmetro. Após, foi realizada a operação final de drenagem por compressão, retirando-se ao máximo o excesso de água. A polpa foi dividida em três porções, sendo uma para controle, outra com adição de albumina de soro bovino (1\%) e a última com adição de clara de ovo (3\%). Os crioprotetores (sorbitol 4\% e tripolifosfato de sódio 0,3\%) foram incluídos em todas as porções. Finalmente, o produto foi congelado e estocado a $-20^{\circ} \mathrm{C}$ até o momento do preparo dos géis.

\subsection{PREPARO DOS GÉIS}

Amostras de surimi, previamente descongeladas, foram misturadas por 2 min aos ingredientes, em cinco diferentes formulações de surimi: (S1) controle; (S2) com albumina do soro bovino (1\%); (S3) com albumina do soro bovino (1\%) e $\mathrm{NH}_{4} \mathrm{Cl}(0,7 \%)$; (S4) com clara de ovo (3\%); (S5) com clara de ovo (3\%) e $\mathrm{NH}_{4} \mathrm{Cl}(0,7 \%)$. Todas as formulações continham $\mathrm{NaCl}(2 \%)$ e amido (5\%). As amostras foram acondicionadas em formas cilíndricas $(2,5 \mathrm{~cm}$ de diâmetro e altura) e submetidas a três tipos de aquecimento em banho-maria: (A) $90^{\circ} \mathrm{C}$ por $15 \mathrm{~min}$; (B) $90^{\circ} \mathrm{C}$ por $30 \mathrm{~min}$; e (C) $60^{\circ} \mathrm{C}$ por $30 \mathrm{~min}$ mais $90^{\circ} \mathrm{C}$ por $15 \mathrm{~min}$. Após o aquecimento, as amostras foram resfriadas para cessar completamente o processo e a seguir embaladas e congeladas para a realização dos ensaios físicos.

\subsection{DETERMINAÇÃO DA FORÇA DE GEL}

A análise instrumental foi realizada em Máquina Universal de Testes (Instron, mod. 1130), utilizando-se célula de carga de $50 \mathrm{Kg}$, velocidades de carta e cabeça de $10 \mathrm{~cm} \cdot \mathrm{min}^{-1}$ e célula plana de pistão chato (35 mm de diâmetro). As amostras cilíndricas com altura e diâmetro de $2,5 \mathrm{~cm}$ foram comprimidas no sentido axial (1/4 da sua altura). A resistência máxima à compressão foi obtida experimentalmente, submetendo-se as amostras até o ponto de ruptura da estrutura (BOYE e LANIER, 1988; SOARES e ARÊAS, 1995). 


\subsection{DETERMINAÇÃO DA UMIDADE}

Para análise da umidade, $5 \mathrm{~g}$ de cada amostra foram submetidas ao método de secagem em estufa, com circulação natural de ar, a $105 \pm$ $3^{\circ} \mathrm{C}$, até peso constante, com três repetições (AOAC, 1995).

\subsection{ANÁLISE ESTATÍSTICA}

O modelo estatístico adotado foi o de blocos inteiramente casualizados, utilizando-se o teste de Duncan para comparação de médias a 5\% de probabilidade de erro. O delineamento experimental contou com esquema fatorial $5 \times 3 \times 3$ (5 formulações, 3 tipos de aquecimento, 3 repetições), sendo utilizado o software Statistic 6.0 (STATSOFT, 2001).

\section{RESULTADOS E DISCUSSÃO}

O efeito dos aditivos protéicos na força de gel baseia-se na proteção da principal característica da proteína (capacidade de geleificação sob aquecimento), intimamente relacionada com a integridade da matriz protéica (LANIER e LEE, 1992). O resultado do teste de compressão, nos géis de surimi de resíduos da pescada-foguete (Macrodon ancylodon) é mostrado na Tabela 1.

\section{TABELA 1 - FORÇA DE COMPRESSÃO (g) PARA OS GÉIS KAMABOKODE SURIMIDE RESÍDUOS DA PESCADA- FOGUETE (Macrodon ancylodon)}

\begin{tabular}{c|ccccc}
\hline \multirow{2}{*}{$\begin{array}{c}\text { Tratamento } \\
\text { tømico* }\end{array}$} & \multicolumn{5}{|c}{ Formula ${ }^{\mathrm{a}} \mathrm{o}^{\star *}$} \\
\cline { 2 - 6 } & $\mathrm{S} 1$ & $\mathrm{~S} 2$ & $\mathrm{~S} 3$ & $\mathrm{~S} 4$ & $\mathrm{~S} 5$ \\
\hline $\mathrm{A}$ & $1866,67 \mathrm{c}$ & $2255,00 \mathrm{~b}$ & $3208,33^{\mathrm{a}}$ & $2325,00 \mathrm{~b}$ & $2483,33 \mathrm{~b}$ \\
B & $2225,00 \mathrm{c}$ & $2433,00 \mathrm{~b}$ & $3026,67^{\mathrm{a}}$ & $2515,00 \mathrm{~b}$ & $2446,67 \mathrm{~b}$ \\
C & $2116,67 \mathrm{c}$ & $2751,67 \mathrm{~b}$ & $2866,67^{\mathrm{a}}$ & $2620,00 \mathrm{~b}$ & $2533,33 \mathrm{~b}$ \\
MØdias & $2069,45 \mathrm{c}$ & $2479,67 \mathrm{~b}$ & $3033,89^{\mathrm{a}}$ & $2486,67 \mathrm{~b}$ & $2487,77 \mathrm{~b}$ \\
\hline
\end{tabular}

Valores médios na mesma linha, não seguidos pela mesma letra, diferem entre si pelo teste de Duncan, a $5 \%$ de probabilidade do erro.

${ }^{*} \mathrm{~A}=90^{\circ} \mathrm{C}, 15 \mathrm{~min} ; \mathrm{B}=90^{\circ} \mathrm{C}, 30 \mathrm{~min} ; \mathrm{C}=60^{\circ} \mathrm{C}, 30 \mathrm{~min}+90^{\circ} \mathrm{C}, 15 \mathrm{~min}$.

** Surimi: S1 controle; S2 com ASB; S3 com ASB + $\mathrm{NH}_{4} \mathrm{Cl}$; S4 com clara de ovo; S5 com clara de ovo $+\mathrm{NH}_{4} \mathrm{Cl}$. 
No tratamento S3, usando albumina do soro bovino como aditivo, o gel kamaboko de pescada-foguete apresentou maior resistência à compressão indicando seu efeito sobre a matriz protéica. A variável que apresentou influência significativa na força de gel foi a formulação, independentemente, do tratamento térmico de acordo com a análise de variância. Na Figura 1 são demonstrados os resultados do teste de compressão.

\section{FIGURA 1 - FORÇA DE COMPRESSÃO (g) DE GÉIS DE SURIMI DE PESCADA-FOGUETE (Macrodon ancylodon) EM RELAÇÃO AOS TRATAMENTOS}

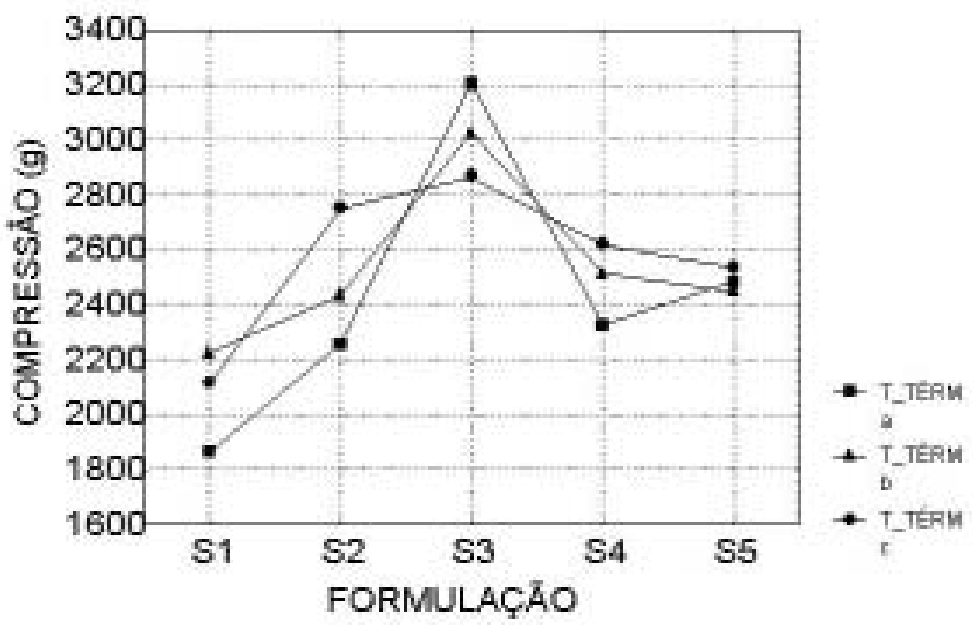

O gel de surimi de pescada-foguete, mesmo sem a utilização de aditivos, alcançou força de compressão média $(2,0 \mathrm{Kg})$ maior que a de géis de surimi de tilápia $(1,0 \mathrm{Kg})$, estudados por BARRETO e BEIRÃO (1999). BOYE e LANIER (1988), estudando o gel de xixarro do Atlântico (Brevoortia tyrannus), encontraram igualmente a média de 2,0 Kg para a força de compressão em géis sem inibidores e igual processamento térmico. O perfil de comportamento nos testes de compressão de surimi de resíduos de pescada-foguete mostrou-se similar ao dos géis de surimi de arenque do Pacífico (Clupea arengus pallassi) estudados por REPPOND et al. (1995). Em condições de processamento similares não foi encontrada atividade proteolítica capaz de degradar o gel, mesmo 
na amostra controle. A presença de aditivos como as proteínas do plasma e da clara de ovo também ocasionaram aumento na força do gel. Para WASSON et al. (1992), o uso de proteínas do plasma bovino como inibidor a $3 \%$ em surimi foi mais efetivo que clara de ovo na mesma concentração. A firmeza e a elasticidade de géis de surimide sardinha (ROUSSEL e CHEFTEL, 1988) e de merluza da Antártida (Merluccius spp) foram estudadas por CHANG-LEE et al. (1990) e MORRISSEY et al. (1993). Os resultados indicaram que albumina do soro bovino e clara de ovo aumentam a força do gel, em relação ao controle, corroborando os dados obtidos neste experimento.

A utilização de superfície de resposta (Figura 2) possibilita visualizar a melhor região de trabalho, sendo possível identificar a variável que apresenta maior influência. Os resultados apontaram que a formulação S3, independente do tratamento térmico, foi significativamente melhor $(\mathrm{P}<0,05)$ em relação ao controle, suportando mais de $3,0 \mathrm{Kg}$ de compressão. Os demais tratamentos, embora superiores ao controle $(\mathrm{P}<0,05)$, não apresentaram diferença significativa capaz de distinguílos entre si.

\section{FIGURA 2 - CARACTERIZAÇÃO DA FORÇA DE COMPRESSÃO (g) DE GÉIS DE SURIMI DE PESCADA-FOGUETE (Macrodon ancylodon) NOS DIFERENTES TRATAMENTOS}

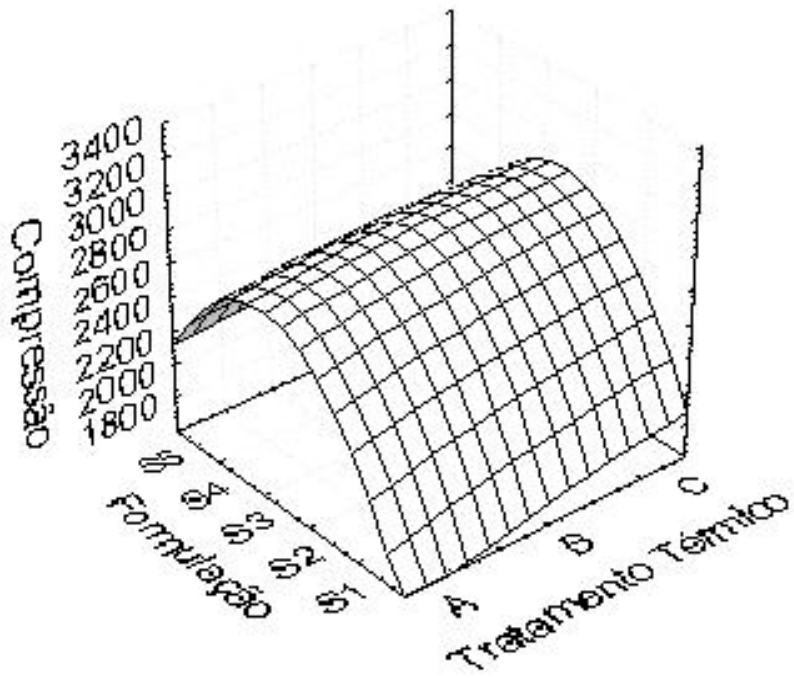


A maior termoestabilidade da albumina do soro bovino pode explicar seu melhor desempenho na força de gel pela presença da fração $\gamma$-globulina (RAEKER e JOHNSON 1995), exigindo assim maior temperatura de desnaturação. SEYMOUR et al. (1997), estudando a albumina do soro bovino em combinação com a fração globulina (FIV1), demonstraram que o aumento da força de gel termo-induzido foi superior ao obtido com a fração isoladamente. Tal fato sugere interação sinérgica entre a albumina do soro bovino e a fração $\alpha_{2}$-macroglobulina $\left(\alpha_{2}-\mathrm{M}\right)$, podendo a albumina do soro bovino formar gel próprio em altas concentrações (>4\%), o que incrementa as ligações dissulfeto e contribui para a estabilidade do gel.

O aumento na força de gel de surimi de pescada-foguete com clara de ovo deve-se à presença de ovostatina, de estrutura molecular e função homóloga à $\alpha_{2}-M$ (WEERASINGHE et al. 1996). Segundo ASHIE e SIMPSON (1996) essa proteína inibiu de modo não-competitivo as proteases catepsina- $D$, tripsina, quimiotripsina e colagenase, controlando sua atividade e de outras enzimas. Apesar de tratar-se de macromolécula, sua utilização em surimi pode ser viabilizada, pois esses produtos apresentam tecido muscular alterado, sem a presença de membranas que possam impedir sua penetração.

O conteúdo médio de umidade do surimi de pescada-foguete alcançou valor médio de $79 \%$ (Tabela 2). O teor de umidade é um dos fatores críticos no processamento do surimie exerce influência na textura do gel kamaboko. Os percentuais de umidade obtidos mostraram-se menores que os encontrados por KUHN e PRENTICE (1999) em surimi de pescada-foguete (82\%). Menor conteúdo de umidade em produtos à base de surimi possibilita a formação de gel com maior qualidade, 0 que se reflete na força de gel. REPPOND e BABBITT (1997) estudando os géis de surimi de merluza da Antártida (Merluccius spp), arenque do pacífico (Clupea harengus) e merluza comum (Merluccius argentinensis), encontraram maior força de gel na faixa de umidade entre 70 e $74 \%$. Os valores de compressão obtidos no presente experimento podem ter sido limitados pelo nível de umidade. A retirada de água no processamento de surimi não foi adequada, necessitando de maior tempo na prensagem da polpa, ou então, indica a retirada do excesso de água por centrifugação. 


\section{TABELA 2 - UMIDADE DE SURIMIDE PESCADA-FOGUETE (Macrodon ancylodon)}

\begin{tabular}{cc}
\hline TRATAMENTO * & UMIDADE $(\%)$ \\
\hline S1 & 79,2539 \\
SASB & 80,2589 \\
SEW & 78,4710 \\
Total & 79,3174 \\
\hline
\end{tabular}

*Surimi: S1, controle; SASB, com ASB; SEW, com clara de ovo.

A presença de ar nos géis também limita a obtenção de maior força de compressão, pois o ar no interior da amostra causa rompimento precoce da sua estrutura durante a compressão. Sabe-se que o embutimento da amostra em tripas de colágeno (resistentes à cocção) e a utilização de misturadores a vácuo modificam a densidade dos géis, permitindo melhores respostas na avaliação da textura.

Os géis contendo $\mathrm{NH}_{4} \mathrm{Cl}$ como inibidor da transglutaminase, associado aos aditivos protéicos, aumentaram significativamente $(P<0,05)$ a força de gel em relação ao controle e aos tratamentos apenas com aditivos. A presença de $\mathrm{NH}_{4} \mathrm{Cl}$ inibiria a ação da enzima, caso estivesse presente, resultando em géis com força de compressão menor. Em géis de surimi de merluza da Antártida, estudados por KUMAZAWA et al. (1995), foi verificada redução de 50\% na força de gel com o uso de $\mathrm{NH}_{4} \mathrm{Cl}$. Tal fato indica a presença de transglutaminase naquela espécie, o que não se confirmou no caso da pescada-foguete.

\section{CONCLUSÃO}

A utilização dos aditivos protéicos aumentou significativamente $(\mathrm{P}<0,05)$ a força de gel do surimi de resíduos da pescada-foguete (Macrodon ancylodon) em relação ao controle.

A albumina de soro bovino (ASB) mostrou-se melhor que a clara de ovo (com diferença significativa), atingindo força de compressão superior a $3,0 \mathrm{Kg}$. 
A utilização do $\mathrm{NH}_{4} \mathrm{Cl}$ não demonstrou interferência da transglutaminase nos géis, indicando ausência da enzima espécie estudada.

Os géis controle (sem inibidores), embora inferiores estatisticamente aos géis com aditivos, evidenciaram boa força de gel, indicando que nas condições em estudo não houve atividade proteolítica capaz de desestruturar a rede protéica.

\section{Abstract}

GEL STRENGTH EVALUATION OF SURIMI FROM BRAZILIAN WEAKFISH (Macrodon ancylodon) WASTES ENRICHED WITH PROTEIN ADDITIVES

The protein additives bovine serum albumin (BSA) and egg white were added to surimi processed from Brazilian weakfish (Macrodon ancylodon) wastes to protect the myofibril protein and to increase the gel strength of kamaboko gels formed during the heating process of surumi. The ammonium chloride was also added $\left(\mathrm{NH}_{4} \mathrm{Cl}\right)$ as a transglutaminase inhibitor to identify the presence of the enzyme, which enhances the texture due to better protein configuration in pre-heating. The instrumental analysis by compression tests revealed that the surimi content additives reached larger gel strength than the control, with BSA being better than the egg white $(\mathrm{P}<0,05)$. The utilization of $\mathrm{NH}_{4} \mathrm{Cl}$ didn't show interference of transglutaminase in the gels, showing absence of the enzyme in the species studied. At the conditions employed, proteolysis capable of denature the gel wasn't characterized.

KEY-WORDS: SURIMI; PROTEIN ADDITIVES; GEL STRENGTH, TRANSGLUTAMINASE.

\section{REFERÊNCIAS}

1 AN, H.; PETERS, M. Y.; SEYMOUR, T. A. Roles of endogenous enzymes in surimi gelation. Trends in Food Science and Technology, v.7, p. 321-326, 1996.

2 AOAC. Association of Official Analytical Chemists. Official methods of analysis of the AOAC international. $16^{\text {th }}$ ed. Arlington, 1995.

3 ASHIE, I. N. A.; SIMPSON, B. K. $\alpha_{2}$-Macroglobulin inhibition of endogenous proteases in fish muscle. J.Food Science, v. 61, n. 2, p. 357-361, 1996.

4 BARRETO, P. L. M.; BEIRÃO, L. H. Influência do amido e carragena nas propriedades texturais do surimi de tilápia (Oreochomis SP.). Ciência e Tecnologia de Alimentos, Campinas, SP, v. 19, n. 2, p. 183-188, 1999.

5 BOYE, S. W.; LANIER, T. C. Effects of heat-stable alkaline protease activity of Atlantic menhaden (Brevoortia tyrannus) on surimi gels. J.Food Science, v. 53, n. 5, p. 1340-1342, 1988.

CHANG-LEE, M. V.; LAMPILLA, L. E.; CRAWFORD, D. L. Yield and composition 
of surimi from Pacific whiting (Merluccius productus) and the effect of various proteins additives on gel strength. J. Food Science, v. 55, n. 1, p. 83-86, 1990.

7 GARCÍA-CARREÑO, F. L. Proteinase inhibitors. Trends in Food Science and Technology, v. 7, p. 197-204, 1996.

8 KUHN, C. R.; PRENTICE, C. Estudo tecnológico para obtenção de surimi utilizando resíduos do processamento de pescada-foguete (Macrodon ancylodon). In: CNPq. Conselho Nacional de Desenvolvimento Científico e Tecnológico. Prêmio jovem cientista: oceanos, fonte de alimentos. Rio de Janeiro, 1999. Cap. 6, p. 181-211. (Publicação dos trabalhos vencedores).

9 KUHN, C. R.; SOARES, G. J. D. Proteases e inibidores no processamento de surimi. Revista Brasileira de Agrociência, v. 8, n. 1, p. 5-11, 2002.

10 KUMAZAWA, Y.; NUMAZAWA, K.; SEGURO, K.; MOTOKI, M. Suppression of surimi gel setting by transglutaminase inhibitors. J. Food Science, v.60, n.4, p.715-717, 726, 1995.

11 LANIER, T.; LEE, C. M. Surimi technology. New York: Marcel Dekker, 1992.

12 MORRISSEY, M. T.; WU, J. W.; LIN, D.; AN, H. Protease inhibitor effects on torsion measurements and autolisys of Pacific whiting surimi. J. Food Science, v. 58, n. 5, p. 1050-1054, 1993.

13 REPPOND, K. D.; BABBITT, J. K. Gel properties from various fish species as affected by moisture content. J. Food Science, v. 62, n. 1, p. 33-36, 1997.

14 REPPOND, K. D.; BABBITT, J. K.; BERNTSEN, S.; TSURUTA, M. Gel properties of surimi from Pacific herring. J. Food Science, v.60, n.4, p.707-710, 1995.

RAEKER, M. Ö.; JOHNSON, L. A. Thermal properties of bovine blood plasma and egg white proteins. J. Food Science, v. 60, n. 4, p. 685-690, 706, 1995.

16 ROUSSEL, H.; CHEFTEL, J. C. Characteristics of surimi and kamaboko from sardines. J. Food Science and Technology, v. 23, p. 607-623, 1988.

17 SEYMOUR, T. A.; PETERS, M. Y.; MORRISSEY, M. T.; AN, H. Surimi gel enhancement by bovine plasma proteins. J. Agricultural and Food Chemistry, v. 45, n. 8, p. 2919-2923, 1997.

18 SOARES, G. J. D.; ARÊAS, J. A. G. Effect of electrical stimulation on Post mortem biochemical characteristics and quality of Longissimus dosrsi thoracis muscle from buffalo (Bubalus bubalis). Meat Science, v. 41, n. 3, p. 369-379, 1995.

19 STATSOFT. Statistic (data analysis software system). Cary, NC, 2001.

20 WASSON, D. H.; REPPOND, K. D.; BABBITT, J. K.; FRENCH, J. S. Effects of additives on proteolityc and functional properties of arrowtooth flounder surimi. J. Aquatic Food Products Technology, v.1, n.3/4, p. 147-165, 1992.

21 WEERASINGHE, V. C.; MORRISSEY, M. T.; AN, H. Characterization of active components in food-grade proteinase inhibitors for surimi manufacture. J. Agricultural and Food Chemistry, v. 44, n. 9, p. 2584-2590, 1996. 